\title{
HOME-MADE OR STORE BOUGHT-TWO APPROACHES TO WORK IN THE LABORATORY \\ by Geoffrey Pill
}

Three years ago I described in this journal a program of "homemade" tapes which I used in my second- and third-year French courses, and I expressed a cautious belief that it was preferable to the "store-bought" commercial tapes which accompany most textbooks. My experience since then has tended to comfirm that belief, while permitting a number of improvements. A recent student evaluation of all foreign language courses in the department suggests that, in general, students are not enamoured of "traditional" tapes and prefer lab work which they feel is "custom-made".

My program is prompted in part by enlightened self-interests: I want a system with which I can live comfortably, and which does not breathe heavily in my ear during class teaching. In essence, work in the lab should constitute a self-contained course, complementing classwork, yet remaining independent of it. I find intolerable the close synchronization of a very tight lab schedule, more or less mathematically worked out, with a hurried progress through a massive textbook. When the slightest deviation or delay in the classroom can throw the class schedule and lab schedule out of synchronization, I feel deprived. So I decided to make my own tapes for second- and third-year courses. I took this opportunity to transfer to the lab those exercises for which there is never enough time in class and which lend themselves to individual activity. In so doing, I hoped to encourage a positive attitude toward the language laboratory.

Ideally, an active, positive attitude would be fostered chiefly by the nature of the work itself. Each tape would be complete in itself, of intrinsic interest, and designed to foster as many of the four language skills as possible: dictations, with insistence that French be spoken before being written; aural comprehensions, with a mixture of written and oral answers to oral and written questions; diction exercises with some written reponse required at some point in the tape. The scope for variety is very great. The student will nearly always have to provide some written proof, however short, of participation; and if no such proof is required, he will not know until the tape is finished.

While the work itself must provide the main incentive for joyful and eager participation, experience has emphasized that the presentation of the program, and the "external" mechanics of the program are of critical importance. $\lambda$ First, the procedures of lab attendance must put the greatest burden of responsibility on the student and at the same time provide him with maximum freedom. He does not go 
to lab at fixed times, for which he must "sign up"; nor does he merely turn to a given channel and listen to a tape played on the console. He must ask for the tape of his choice, take it to his booth, put it on, rewind it at the end, and return it. He is free to stop and replay as he wishes. He can, for example, choose to do half a dictation instead of a whole one, and listen to it twice as often. Because the tapes are independent of the textbook, varied in type, and loosely graded in difficulty, it does not matter if the tape a student wants is already checked out: he can take another near number and do the missed one later. Students seem to appreciate the freedom to go to the lab when-they please, and rarely abuse it.

Secondly, the importance attached by the teacher to the broad and varied exposure to French offered in the lab must be made manifest in class. Laboratory sessions begin on the second Monday of semester, to avoid confusion and unseemly haste in the first hectic week. During the first week, the purpose of the lab program must be made clear, and the full schedule given out, including all required work-sheets. The place of lab performance in the overall grading scheme is mentioned. The lab schedule identifies each tape by a number, the type of exercise chiefly involved; the materials needed; and a title. It is accompanied by a commentary sheet, where each tape is listed with space for students to give it a grade, and make their criticisms. Collected at the end of the semester, the comemntary sheets permit constant improvements in the program. Written lab work, which is passed on to the teacher by the lab assistant, is regularly returned in class; where appropriate, a correct version, with notes or material to be learned, is stapled to the student's copy. Lab work is, with due notice, incorporated in tests. Students are reminded to complete their commentary sheets. In general, the aim is to keep the student aware that the teacher considered lab work an integral part of the course. The fact that he has bothered to make up the program is in itself strong initial evidence of his concern; and the constant interplay of lab and class, without either one in any way dictating or interfering with the other, continues the impression.

Such, briefly, was the program I described in 1972, and which I have continued since. This article merely summarizes some results of a recent student evaluation of foreign language courses which suggest that students, irrespective of the technical merits of the tapes, prefer work in the language lab to be varied, active, and individualized; and that pattern-drills, however excellent in theory, are somewhat dull in practice and might better be confined to the classroom. 


\section{Home-Made}

The questionnaire, completed by all foreign language students in December, 1973, was the first one composed entirely by the Foreign Language Department, and we were able to include questions of particular interest to our own discipline. So, after 18 questions dealing with the teacher and the course, we included three in a separate section concerned specifically with the lab. These were:

"IF LANGUAGE LABORATORY IS REQUIRED, did the work done in the language lab seem to you:

\section{Q. 19. WORTHWHILE AND CONSTRUCTIVE

$\begin{array}{lllll}5 & 4 & 3 & 2 & 1\end{array}$ \\ Nearly always Generally Sometimes Not often Useless}

Q. 20. ENJOYABLE AND SUFFICIENTLY VARIED

$\begin{array}{ccccc}5 & 4 & 3 & 2 & 1 \\ \text { ly always } & \text { Generally } & \text { Sometimes } & \text { Not often } & \text { Boring }\end{array}$

Q. 21. DIRECTLY OR INDIRECTLY APPROPRIATE TO THE COURSE

$\begin{array}{ccccc}5 & 4 & 3 & 2 & 1 \\ \text { y always } & \text { Generally } & \text { Sometimes } & \text { Not often } & \text { Never }\end{array}$

Nearly always Generally Sometimes Not often Never

The results were collated in three colums: (1) Rating on Questions 1-18; (2) Rating on Questions 19-21; and since if lab attendance is required it seems reasonable to include lab ratings in the overall assessment, (3) Rating on Questions 1-21.

Believe me, dear, reader I am fully aware of all the problems and pitfalls of student evaluations: size, level, homeogeneity of class; presence of unwilling conscripts satisfying a language requirement, etc. I take such evaluations with a sizeable pinch of salt. And I have no taste for invidious comparisons, particularly for comparisons involving decimal points. Nothing in this article is intended to reflect in the slightest on any colleague, for I am fortunate enough to be surrounded by excellent teachers. But the results in general, while they might lack "significance" in any precise statistical sense, do appear to back up the case for home-brewed laboratory programs. The overall results were, in fact, gratifying. For the full department program, including courses with lab work and courses without, the average scope was about 4.5. But when only courses requiring lab attendance are considered ,some interesting trends emerge.

In first year French and Spanish, where multiple sections involve a common schedule shared by several teachers using commercial tapes, the teacher averaged 4.48 under Questions 1-18. For Questions 19-21, the average was 2.95, a drop of 1.53 on the 5-point scale. 
In the second year, when the university foreign language requirement ( 10 hours of a foreign language for the BA) has been satisfied, enrollment is restricted to better motivated students; and the lab ratings are higher accordingly. In the two sections of the one Spanish course requiring lab attendance, Questions 1-18 rated the teachers at 4.54; Questions 19-21 evaluated the lab, where commercial tapes were used, at 3.36: a drop of 1.18. In second year French and German courses, the evidence in favor of "individualized" lab programs ibegins to appear. I did not teach any second year that semester, but two French courses used the system I have described. In one, the teacher mixed tapes made by herself with tapes made by other colleagues, including some of my own; in the other, a set of tapes which I had made earlier for the same course was used in its entirety. The differences in ratings between Questions 1-18 and 19-21 were: for the former - 0-80; and for the latter - 0.31.

In only two courses was the lab work rated above 4 . The first was a second-year German course, in which the teacher made her own tapes and created a program embodying roughly the philosophy described above. In this case, the lab rating, at 4.53, was the highest of all, and fell only 0.22 below the rating for Questions 1-18. The overall rating for the course, including all the questions 1 through 21 , was the highest in the department.2

The only third year course for which lab attendance was required was French, Advanced Composition and Conversation. This course used the type of program outlined earlier in this article. In this case, the lab rating (Questions 1-19) was 4.52 , only 0.04 below the teacher rating on Questions 1-18.

It seems reasonable to conclude that the "home-made" lab program appeals to students, and that it does so largely because of the variety, the freedom, and the sense of individual targeting which it can engender. Not that these are any grounds for complacency! The regular feedback from the students is an unfailing school of humility. One makes it clear that only honest comments are of any value, and they can be very honest! There is never time to make all the improvements one would like, either in individual tapes or in the program as a whole. But the results of the evaluation were at least encouraging enough to suggest that the principles is sound, and that it is worthwhile to keep on trying.

1 Geoffrey Pill, "How to use the Language Lab without Actually Feeling Guilty," NALLD Journal, 5, No. 4 (1971), 35-42.

2It is to be hoped that the teacher who achieved this rating, Professor Hilde Wohlert, will describe her lab program in a future article. 